\section{The ASPET Mentoring Network: Enhancing Diversity and Inclusion through Career Coaching Groups within a Scientific Society}

\author{
Veronica Y. Womack, ${ }^{\dagger}$ Bhoomi K. Thakore, ${ }^{\ddagger}$ Christine V. Wood, ${ }^{\S}$ David C. Jewett, ${ }^{\pi}$ \\ Remi F. Jones," Susan L. Ingram, ${ }^{\circledR}$ Janet A. Clark, ${ }^{*}$ Catherine L. Fry, \\ Lynn Wecker, ${ }^{* *}$ and Richard McGee ${ }^{\| *}$ \\ tSearle Center for Advancing Teaching and Learning, Northwestern University, Evanston, IL 60602; \\ "Department of Sociology, University of Central Florida, Orlando, FL 32816; `Medical Social \\ Sciences and 'Faculty Affairs, Northwestern University Feinberg School of Medicine, Chicago, \\ IL 60611; 'Neuroscience Program, Department of Psychology, University of Wisconsin-Eau Claire, \\ Eau Claire, WI 54702; ‘ Department of Neurological Surgery, Oregon Health \& Science University, \\ Portland OR 97239; \#National Institute of Mental Health Intramural Research Program, National \\ Institutes of Health, Bethesda, MD 20892; "American Society for Pharmacology and Experimental \\ Therapeutics, Rockville, MD 20852; ;"Department of Psychiatry and Neurosciences, University of \\ South Florida Morsani College of Medicine, Tampa, FL 33612
}

\begin{abstract}
Over the past decades, two persisting priorities in science, technology, engineering, and mathematics (STEM) training have been: 1) increasing the knowledge of and access to careers beyond academic scientist; and 2) increasing the diversity of the STEM workforce. Previous studies show that a uniquely constructed career coaching group provides strong support and progress for both priorities. This report extends this design into a more sustainable model that is positioned within the professional context of rising young scientists. This new model is based in the American Society for Pharmacology and Experimental Therapeutics (ASPET)-the ASPET Mentoring Network. Groups of PhD students and postdocs were assigned to an ASPET professional (academic or other career) member (the coach) with an initial meeting held the day before the society's annual meeting. The coaching groups interacted during the meeting and then virtually for a year. Extensive survey and interview evaluation data gathered from the first three cohorts (12 coaching groups) in 2016- 2018 provided strong evidence of the perceived and real benefits of the network. This new version of career coaching groups is both feasible and linked to career success due to its close association with a scientific society, peers, and coaches who share scientific identities and aspirations.
\end{abstract}

\section{INTRODUCTION}

Over the past two decades, there has been an intensive and extensive focus on the training and outcomes of young life scientists in the United States. In many respects, there has been a sea change in the value placed on career outcomes, from seeing anything other than a faculty position as an "alternative career," to the recognition of the high value of many career outcomes. A number of consensus study reports and meeting proceedings of the National Academies of Science, Engineering and Medicine have focused on the topic (NASEM, 2011, 2014, 2018), as have many working groups of the Advisory Committee to the Director of the National Institutes of Health (NIH). For many years, $\mathrm{NIH}$ has required that all trainees on $\mathrm{F}$, T, and $\mathrm{K}$ awards have individual development plans (IDPs) and the National Science Foundation has required that any grant requesting salary support for a postdoctoral fellow (postdoc) include a postdoc
Rebecca Price, Monitoring Editor Submitted Oct 11, 2019; Revised Apr 16, 2020: Accepted Apr 28, 2020

CBE Life Sci Educ September 1, 2020 19:ar29 DOI:10.1187/cbe.19-10-0195

*Address correspondence to: Richard McGee (r-mcgeeanorthwestern.edu).

(c) 2020 V. Y. Womack et al. CBE-Life Sciences Education ๑ 2020 The American Society for Cell Biology. This article is distributed by The American Society for Cell Biology under license from the author(s). It is available to the public under an Attribution-Noncommercial-Share Alike 3.0 Unported Creative Commons License (http://creativecommons.org/licenses/ by-nc-sa/3.0)

"ASCB®" and "The American Society for Cell Biology $\AA^{\circ}$ are registered trademarks of The American Society for Cell Biology. 
mentoring plan (NSF, 2009). From these and other contributions has emerged a consensus that more needs to be done to provide systematic guidance for graduate students and postdocs, such as has been developed through the Broadening Experiences in Scientific Training (BEST) awards (Lenzi, 2020). Recently, the National Institute of General Medical Sciences, the $\mathrm{NIH}$ institute with the largest training portfolio, has revised its training grant awards to require much broader training and systematic focus on the learning aspects of the training, including training of faculty in mentoring skills (NIGMS, 2017).

Over the same period of time, a strong focus on increasing racial/ethnic and gender diversity in the scientific workforce has mirrored the emphasis on broadening training. Diversity initiatives and programs have gone through extensive review and evolution in both design and the environments/institutions where they take place. One of the newest efforts was NIH's creation of the Diversity Programs Consortium (DPC, n.d.). The goals of the DPC are to: 1) increase access to virtual mentoring across all training stages, but especially undergraduates and graduate students; 2) expand the reach of research training to a larger number of diverse undergraduates; 3 ) increase the reach of evidence-based training to improve mentoring skills; 4) create new approaches to promote culturally aware mentorship (CAM); and 5) deploy a number of group-based faculty-led coaching and mentoring models that had shown evidence of success in other settings.

The research group contributing to this current report, the Scientific Careers Research and Development Group (SCRDG), has been involved with multiple aspects of these initiatives, including a large-scale longitudinal qualitative study of the career evolution and choices of biomedical PhD students (Gazley et al., 2014; Remich et al., 2016, 2017); development and testing of a new workshop-based approach to teach CAM (Byars-Winston et al., 2018); a group-coaching model for teaching and modeling the complex skills of grant writing (Jones et al., 2017); and a randomized controlled trial of a novel group-based career coaching and mentoring model called the Academy for Future Science Faculty (hereafter "the Academy"; Thakore et al., 2014; Williams et al., 2016a,b, 2017). One key element of the Academy is its conscious attention to creating diverse groups that are becoming and will continue to become more common in the future. Based on a great deal of research and evaluation data, these new approaches are seen by participants as highly valuable and contributing positively to their scientific growth and development in different ways and for different individuals. However, none of them have focused explicitly on including attention to the evolution of scientific identity during and beyond graduate school. Scientific identity starts out typically with a general identification with science, discovery of new knowledge, problem solving, and so on (McGee and Keller, 2007). Beginning during PhD training, identity starts to focus more into a specific research area situated within one or more scientific domains. Achieving this disciplinary identity and a sense of acceptance within it is a critical element of both persistence and developing professional networks essential for success. This is why scientific societies devote resources and effort to encouraging students and postdocs to attend their national meetings, often through travel fellowships. And, at those meetings, societies provide carefully planned programs to bring these young scientists into their communities. Many scientific societies also put special efforts into welcoming underrepresented (UR) young scientists. Thus, it seemed appropriate and logical to see if it was possible to bring elements of many of the different initiatives described earlier and situate them within a scientific society environment.

This report describes the first introduction of a career coaching group design into a scientific society framework through the American Society for Pharmacology and Experimental Therapeutics (ASPET). The terms "coach" and "coaching group" are used rather than "mentor" and "mentoring group" to distinguish the approach from traditional research mentors and mentoring in ways that are described more fully later. ASPET is a 5000-member nonprofit scientific society whose members conduct basic and clinical pharmacological research within a variety of sectors. The first ASPET Mentoring Network (hereafter "the Network") cohort of $24 \mathrm{PhD}$ students and postdocs was launched in 2016. The 24 individuals were divided into four groups with four $\mathrm{PhD}$ students, two postdocs, and a professional-level ASPET-member coach. Virtual meetings continued for a year after the in-person meeting the day before the annual ASPET meeting. The program in 2016 and 2017 was funded by an ASPET initiative to launch innovative new programming at the annual meeting. The response by both participants and mentors was so positive that the ASPET Council decided to sustain the program beyond the initial award period into 2018. In 2018, a grant from the Burroughs Wellcome Fund enabled a 2019 cohort to increase to 36 participants with six coaches. The Network was not designed as an experiment with control or comparison groups, but rather as a program to evolve and evaluate each year, similar to other professional development programs within scientific societies. This report describes the design, evolution, and evaluation data from the mentees, the ASPET coaches, and the SCRDG members who observed the in-person meetings the day before the ASPET annual meeting. Data from the first three cohorts are included. The report also describes the unique training provided to new coaches to introduce them to the theoretical underpinnings of the group design and how to facilitate the interaction between members of the purposely constructed diverse groups.

\section{METHODS}

\section{Network Framework}

As established through our previous work (Thakore et al., 2014; Williams et al., 2016a,b, 2017), supplemental mentoring networks are useful for helping early-career scientists navigate the individual dynamics of the professional world. Additionally, group mentoring connects mentees to not only an outside mentor (who brings his or her own experiences to career advising), but also a group of colleagues who are at comparable earlycareer stages.

\section{Career Coaching Group Design}

The design of the coaching groups started from the conceptual framework of the Academy. Briefly, it starts from the assumption that the opportunities and experiences of students during the $\mathrm{PhD}$ years are highly variable for many reasons. In particular, knowledge of career options and the skills required to achieve them is unevenly available across research mentors and at different institutions. This can lead to lack of knowledge and concerns about achieving career options. 
Additionally, individuals from UR or marginalized groups are at higher risk of insufficient mentoring, leading to lower sense of self-efficacy with respect to a given career goal. Feelings of not belonging and the imposter syndrome can lead to further risks of not progressing in a given career. Expressing these feelings can be very difficult within a training environment in which one needs to perform and appear confident in order to not jeopardize perceptions of competence within that community. All of the potential challenges, which are not only faced by UR trainees, can be ameliorated at least to some degree by a coaching group led by an accomplished professional in the field. Our previous studies have shown that the unique benefits of the groups derive from the combination of trusted peers and the independent mentor or coach. To achieve this trust, however, the group and mentor must be perceived as safe, supportive, and with no competing or conflicting interests with respect to sharing personal concerns. The ASPET Mentoring Network was set up with the intent to achieve all of these goals.

\section{Social Science Theories Underpinning the ASPET Mentoring Network}

Becoming successful in any profession requires acquisition and display of the cultural capital that established members of a group or field recognize as indicative of those who "belong" in it. From the classical work of Bourdieu (1985), cultural capital is the ways of knowing and behaving tied to socioeconomic class that family and others pass on to younger generations, often unknowingly. Cultural capital is highly contextual; knowing and behaving appropriately in one setting often does not translate to another setting. Thus, cultural capital associated with science professions is not universally or evenly available to all. Within a science and research perspective, there is wide variation in the degree to which young scientists are exposed to and provided with the cultural capital of successful scientists. Ideally, research mentors should make sure all trainees have access to the cultural capital appropriate to their fields, but too often this does not happen. The Network was designed to provide access to the knowledge and skills and ways of acting as a successful scientist to complement or fill in the gaps left unfilled by research mentors. The combination of successful coach and peers plays a unique role to combine direct teaching/explaining with vicarious learning through the group process.

As an extension, as novices work to emerge as successful professionals, they encounter the workings of communities of practice (Lave and Wenger, 1991; Wenger, 1998). The work of Lave and Wenger has vividly revealed how these communities with shared goals, practices, knowledge, and ways of working serve as the units within which new professionals must work to establish their legitimacy. But often the knowledge and practices are not made explicitly known or visible, and "newcomers" have to somehow figure out what is expected for one to be seen as a legitimate member. Science behaves exquisitely as a series of communities of practice, ranging from individual research groups up through scientific fields and a larger community of science. Scientific societies like ASPET play critical roles in helping young scientists learn and master the behaviors and expectations of the field. The Network was directly designed to consciously and purposely enable this to happen by linking students and postdocs with successful ASPET members who were charged to work from students' and postdocs' interests and questions to guide them into feeling welcome and successful in ASPET and the field.

Finally, the Network is designed to address the difficult-to-avoid limitation of research mentoring at the graduate student and postdoc levels, where mentors may find it difficult to accept and/or play an active role in guiding mentees toward careers different from their own. Trainees often are hesitant to reveal career and life interests different from those of their mentors due to concern these could influence how they are viewed, evaluated, and "promoted" in recommendations and letters for future positions. The Network provides access to additional mentors/coaches with no evaluative role or competing interests with whom trainees can be fully honest.

\section{Selection and Training of Coaches}

Coaches were chosen initially from members of the ASPET Mentoring and Career Development Committee and based on their desire to provide mentoring to their junior colleagues. Over the 3 years (2016-2018) reported herein, 11 coaches participated; two coaches led groups in two cohorts. Of the 11, seven are women and four are men, 10 are white and one Asian, six are in academia (one primarily teaching), four in industry, and one in government. (Due to the success of the program and increased interest throughout ASPET, coaches in 2019 and 2020 are more diverse in race and ethnicity.)

\section{Coach Training}

In the original Academy design, coaches were provided with a 2-day training program that immersed them in its social science theoretical underpinnings and preparation for the intensive and extensive group experience ahead. Most found this training very valuable, but the time and cost was not sustainable. Therefore, a more condensed training was developed. A few weeks before each cohort kickoff, coaches were oriented to the Network design in a 1-hour teleconference led by members of the SCRDG. After the call, coaches were provided with background reading about the Academy group mentoring design; research findings from the Academy; the social science theories upon which the design is based; and short articles that address some of the extra concerns, pressures, and racialized assumptions and treatments in society and research settings (Sue, 2013; Harrison and Tanner, 2018). The goal of the later readings was to help coaches prepare to lead the diverse mentoring groups.

In addition to these premeeting materials for coaches, all of the coaches and mentees were asked to complete two premeeting activities. First, coaches were asked to spend 60-75 minutes going through an online module that introduces some critical concepts and terminology around diversity and inclusion, and the realities of differential experiences both inside and outside science. It provides language and context for concepts including microaggressions, stereotype threat, bias, and ongoing discrimination. Second, coaches were asked to prepare a "culture box" per the instructions included in the Supplemental Material. Briefly, they were asked to identify and bring with them three physical objects (or pictures of them) representative of important aspects of their personal, cultural, and racial/ethnic identities-how they see themselves outside science. The role that the culture boxes play in the kickoff of the groups is described later. Both the online module and the use of the culture box and 
elements of a daylong workshop on CAM were contributed to by two of the authors (V.W. and R.M.; Byars-Winston et al., 2018).

The day of the Network kickoff, two members of the SCRDG (R.M. and V.W.) met with the coaches for 2 to 3 hours to discuss the readings, go over the agenda for the Network, talk through how mentoring a group can be similar and different from mentoring individuals, their experiences completing the online module and culture box activities, some types of "difficult conversations" that might arise, and any remaining questions.

\section{Selection of Network Mentees}

The ASPET education director (C.L.F.) created an online application through which $\mathrm{PhD}$ students and postdocs who were members of the society could apply to join the ASPET Mentoring Network. The application requested basic information about the applicant, including demographic information (name, current address, and self-reports of gender and race/ethnic backgrounds), prior undergraduate and graduate schools attended, current year in graduate school (graduate student applicants) or prior and current postdoctoral experience (postdoctoral applicants), and future career plans (i.e., academic, industrial, or government positions). Importantly, the application requested a short statement of interest and what the applicants hoped to gain from the program. The application specifically did not request a letter of recommendation, as we did not want to discourage applicants who may be experiencing difficult relationships with their university mentors. The program was advertised through ASPET's marketing channels, including social media, webpage, monthly newsletter, and membership magazine. Review of applicants was handled by a group of volunteers from the ASPET Mentoring and Career Development Committee. Selection was based on a combination of the applicant's career goals, personal statement, and evidence of readiness to participate meaningfully in the program.

Selected applicants were assigned to groups, paying attention as much as possible to: 1) equal numbers of men and women in each group; 2) diversity in each group with respect to racial, ethnic, and United States versus other countries of origin; and 3) similar career interests or goals. This last criterion was sometimes hard to apply, as many were "undifferentiated" and actually seeking to be part of the Network to get help figuring out a career path to pursue.

Each coaching group included four PhD students and two postdocs. The group size of six was chosen to limit demand on each coach but still have enough members for good group dynamics. Feedback from coaches confirmed that six was a good size. Students and postdocs were combined to meet the ASPET mission of reaching both groups and ideally enabling near-peer mentoring across career stages. Starting in 2018, applications from graduate students were limited to those who had advanced to candidacy. The diversity of the overall population ( $n=69$, because three people dropped out) is provided in Table 1.

\section{Kickoff and Subsequent Activities of the Network}

The kickoff meeting of the Network began with introductory activities, culminating with a social mixer on the day before the ASPET annual meeting at the Experimental Biology meeting. The schedule for the kickoff for 2018 is provided in the Supple-
TABLE 1. Mentee demographic data $(n=69)$

\begin{tabular}{lr}
\hline Demographic data & Total \\
\hline Racial/Ethnic background & \\
White & 27 \\
Asian & 17 \\
Black/African American & 15 \\
Hispanic/Latinx & 5 \\
Two or more groups & 4 \\
Pacific Islander & 1 \\
Gender & \\
Female & 41 \\
Male & 28 \\
Educational status & \\
Graduate student & \\
Postdoctoral scholar & 47 \\
Career Interest & 22 \\
Academia & \\
Government/policy & 27 \\
Industry & 13 \\
Undecided & 19 \\
Country of origin & 10 \\
United States & \\
India & \\
Mexico & 14 \\
New Zealand & \\
Egypt & 30 \\
Ghana & 10 \\
Cameroon & 3 \\
Chigeria & 2 \\
Vietnam & 2 \\
Hungary & 1 \\
Philippines & 1 \\
Lebanon & 1 \\
\hline Unknown/not specified & 1 \\
\hline
\end{tabular}

mental Material. Mentees did not know which group they were in during this first meeting to promote broader networking and social connections among all participants. The activities and the schedule of the in-person meeting evolved over the 3 years of the Network based on feedback from mentees and observations of leaders of the program. The Friday afternoon session was designed to provide a framework for the program and initiate camaraderie among all of the mentees and coaches. The debrief of the online CAM module provided the opportunity for discussion and opening the door to future conversations within each group. The activity around group facilitation introduced the idea that everyone in the Network groups will be a facilitator, not just a participant. Finally, the social function contributed to building rapport with colleagues.

On Saturday morning, mentees were given their group assignments and sat with their groups. After a short introduction, the morning began with individuals taking turns sharing the contents or pictures in their culture boxes, why they brought an item, and what the item meant to them. Coaches began the activity to model that they had cultural and personal identities beyond science, and it was not only okay but interesting to get 
to know them as people. This exercise turned out to be an extremely effective "icebreaker" to enable group members to get to know one another in much more personal ways than is typical for mentoring groups. The impacts of this exercise are described in the Results. After this activity, the facilitators introduced the IDP as a tool to think explicitly about future career goals and the actions needed to achieve them. The rest of the morning was spent in groups, continuing to get to know one another and determining what each person hoped to get from being in the Network. Each group was tasked to establish a plan for what they would like to accomplish in the future virtual meetings. At the end of the morning, each group reported out what they hoped to accomplish to trigger ideas across groups and sometimes collaborations. The formal part of the day ended with a lunch that brought together all of the new Network members with alumni Network members who were attending the ASPET annual meeting. This aspect of the program was added after the first year of the program to enhance the continuity of the program.

After the in-person group meeting, coaches were asked to schedule about 30 minutes to meet individually with each of their group members during the ASPET meeting. This allowed for more personal conversations and identification of mentoring needs not as amenable to the first group discussions and to address mentoring needs that were not identified during the formal sessions. Some groups chose to identify other times during the ASPET meeting where all or some came together. After the end of the ASPET meeting, each group took on the responsibility to manage their virtual meeting times and content. Monthly virtual meetings were recommended, but each group was free to determine its own schedule. Monthly meetings were done by phone, Skype, WebEx or other such platforms that were amenable to bringing the group together for discussion. Individuals were encouraged to connect with one another directly as well and to schedule individual time with their own or other coaches as desired. An ASPET Mentoring Network LinkedIn group was established to foster networking and communication between current Network coaches and mentees as well as with alumni Network coaches and mentees.

\section{Program Evaluation and Feedback Data Collection}

Mentees completed online surveys at three time points: 1) immediately after the kickoff event, 2) at the end of the ASPET annual meeting, and 3) 10 months later at the end of the program. Telephone interviews were also conducted with mentees at the 10-month time for cohorts 1 and 2. The coaches were also surveyed immediately after the kickoff and interviewed at the 10-month time point. The survey questions and interview protocols are included in the Supplemental Material. Surveys contained a mixture of scaled responses and open-ended questions. The goal of the analysis was an overall assessment of the Network and how mentees and coaches experienced it/saw its value. About half of the participants in each of cohorts 1 and 2 (12 and 13 individuals, respectively) responded to invitations for a phone interview. They represented a full array of genders and races/ethnicities. No comparisons between demographic groups, individual coaching groups, or cohorts are made due to the small number from any one race, ethnicity, and/or gender combination; the goal was to evaluate the overall coaching group design. The Network and program evaluation data gathered were reviewed by the Protection of Human Subjects Committee of FASEB, of which ASPET is a member, and determined to be exempt from institutional review board review consistent with exemption criterion 1 of Department of Health and Human Services regulations.

\section{Analysis and Validity of Qualitative Text and Interview Data} In qualitative studies involving interviews and participant reflections, it is important to consider issues of internal and external validity and the four pillars of validity in qualitative research methods-credibility, dependability, transferability, and confirmability. Internal validity is most germane to a study such as this, which is drawing conclusions about the study participants and not making claims to generalizability or reproducibility. Thus, a discussion of external validity, for the purposes of establishing rigor, is beyond the scope of the paper.

The study meets the criterion of credibility based on the consistency and content of its methodological instruments. The survey and interview protocols were uniform and administered to participants at specified time points. The interview protocols were semistructured and asked participants to recall and provide, in their own words, their perceptions of the in-person meetings and the virtual group meetings during the year. They were asked about scheduling and organization as well as the impacts, if any, of the coaching groups. Interviews occurred near the end of the yearly cycle after 9 to 10 months of group meetings. The participants' narratives were the data; initial coding corresponded with their statements in the interview. The analysis was free from framing from an outside theory, with a descriptive coding structure that sought statements about the impacts of the program and the coach/coaching group.

The study is dependable in the same way that it is credibleit relies on consistent, uniform, and regularly administered data-collection tools.

The criterion of transferability does not apply to this study, as it makes minimal claims to generalizability or external validity. The evaluation data do reveal perceived benefits of those in the Network, with particular attention to promoting career clarification, professional networking, and being part of a diverse community. It is not unreasonable to expect a similar coaching group model enacted by another scientific society would provide similar benefits, but evaluation data cannot speak to that possibility. Studies with high internal validity and modest claims to transferability are common in qualitative methodology.

The criterion of confirmability is achieved, because the entire authorship team was involved in the analysis. All members share the same understanding of the procedures used to administer the interviews, collect data, and code for relevant themes. Not all team members were involved at all levels of analysis, but all confirmed the appropriateness of the coding scheme and characterization of statement assigned to each theme. This coding scheme was not grounded in a particular theory or analytic approach and relied entirely on participants' responses. This thematic framework was agreed to by the group after carefully examining the initial data. 


\section{RESULTS}

\section{What Takes Place during In-Person Meetings?}

Establishing Group Cohesion, Trust, and Connections. While dyadic mentor-mentee relationships are solely dependent on the engagement of both parties, maintaining a cohesive coaching group is dependent on a variety of factors. For example, how engaged are individual group members with one another and with the group? How effectively does the group "gel"? Is trust established among group members and the coach? The degree to which individual members share, engage, and connect with one another will determine the extent to which they learn and benefit from the group and the coach. Trust is very important for the most effective mentoring to take place.

The first real meeting of the coaching groups began as everyone found their groups and sat with them before the start of the Saturday morning meeting. Observing the groups, one could see the beginning of people getting to know one another, primarily with typical questions like career stage, university, research and career interests, and so on. When the culture box activity began, there often was a brief awkwardness concerning where to start. This was quickly abated by the coach sharing his or her culture box. Usually within minutes, the entire "affect" of the room changed with total focus on the person sharing his or her items in each group, animated conversation, emotion-infused responses, and engaged dialogue. It was impossible to miss how much thought and effort almost everyone had put into their choices, but also often with expressions of it being a difficult task initially. Emotions portrayed by each storyteller varied, but most displayed facial and voice expressions of pride, joy, meaning, and sometimes tears.

Some individuals and groups took longer to engage with one another, but with few exceptions, the allotted time of 5-10 minutes per person soon was being exceeded by most groups. Again, from simple observation and listening, the conversations were noticeably different from those that preceded the culture box and those that would normally occur (if at all) within the context of a scientific meeting. Almost everyone shared stories that promoted connection among mentees and coaches that never would have been revealed if not for the culture box. The idea that diversity exists everywhere came out, as did the concept of diversity within categories, even within "white." This was the first time in which this activity was "imported" from the CAM training, but the culture box activity had almost exactly the same effect in both settings. The activity gives (actually requires) the opportunity to share important non-science identities and personal situations, but with no requirement to share anything a person does not want to. It also gives others permission to be curious and ask questions that one otherwise may be hesitant to ask.

From the postmeeting surveys, both the coaches and group members noted that the culture box activity was an important introductory process for establishing their groups and "bringing them closer together." A coach from the first cohort explained, "The group culture box was a great way to introduce and get to know each of the group members." The learning and openness that took place during this activity laid the groundwork for comfortable, in-depth discussions in the future. Other specific comments:
"The culture box allowed me to learn a great deal of personal information about my group members, providing a more intimate relationship to be formed from the very start."

"This was a very helpful exercise to learn about others in your group. Considering we will be interacting for at least the next year and likely longer, it is good to be able to remember and relate to the people in your group."

"Through culture box, people opened up more easily about their lives in general."

"It allowed us to care more about one another and definitely made us closer."

When asked to describe the strengths of individuals in their group as they interacted with one another during the meeting, the coaches noted that their group members were "engaged," "open," "honest," and willing to "provide feedback and help each other." Two group members supported these observations when asked about the unexpected aspects of the Network, stating:

"I was surprised with how quickly a bond formed with my group. I really want to support them, and receive their support."

"I loved the interaction we had with the group. I loved how open I could be in discussing my experiences. It was amazing to find a safe space to discuss problems and difficulties."

One coach explained, "We are diverse enough that they all help one another. They listened to one another, and they all spoke. They were gracious but challenging, admitting strengths and weaknesses." The "diversity" that this coach and other coaches referred to pertained to the diversity of their experiences as either graduate students or postdocs, enabling them to "provide advice to each other." The coaches were impressed with "how everyone seemed to participate equally" and their "maturity, mutual respect, and active listening abilities." A coach from the third cohort added to the perceptions of mutual respect among the group members stating,

\begin{abstract}
"There seemed to be a good appreciation of each individual's story and goals. Individuals were humble but also very motivated and joyful. There seemed to be a good appreciation within the group of the role of others in supporting their development and success."
\end{abstract}

The coaches also described the challenges that they observed in their groups. One mentioned that some members might be more focused on their own needs or agendas and that she would have to balance this with the group's common interests. Two other coaches acknowledged that personality styles may present a challenge, noting that some members are more "vocal" or "dominating" than others. Therefore, the coaches were aware that they would have to keep "the shyer individuals participating and contain the stronger personalities from dominating" the upcoming phone conversations. 
Increasing Awareness of the Social Factors That Influence Science Identity and Inclusion. The utility of understanding social science theories in the context of scientific or laboratory settings was a key component of the programming across all three cohorts. The evaluations revealed that this discussion helped them label their experiences and understand how they are perceived by others as well as the cues that they may subconsciously look for to assess their levels of competency. These theories and concepts helped them deconstruct their experiences in a manner that did not lead to the internalization of criticism, but instead to view criticism as normal and an aspect of developing one's identity as a scientist.

"I learned that I can be considered, as a first timer, [an] incompetent person until I become proactive and participate."

"I struggle a lot personally with self-efficacy and it was helpful to hear about self-assessment and external recognition and feedback when thinking about [what] I am good or bad at."

"It helped me understand some behaviors that my boss may [have] had before and helped me understand that his actions weren't personal with me, but part of general social behavior."

The programming also included a discussion on the "social aspects of thriving as a scientist," which focused on the experiences of individuals who may be marginalized in science settings due to being the only one or one of a few from their gender or racial/ethnic group. In the last two cohorts, the online module provided much more information on the historical events and social psychological factors (e.g., unconscious bias, microaggressions) that informed the disproportionate number of individuals from U.S. minority communities in science. The online module also provided more detailed information and time to process and reflect on it before coming to the Network. The increased and deeper conversations in the second two cohorts was very obvious. Both the module and the discussion encouraged the mentees to be introspective and reflect on their roles both in perpetuating and disrupting systemic racism in scientific settings. Many spoke about being more conscious of ensuring that their language and actions are culturally sensitive. Some mentees who identified with marginalized communities reported feeling affirmed and believed that the Network would be a supportive space to share their stories. The mentees also spoke about how this information would inform their steps to intentionally create inclusive lab environments when they become principal investigators (PIs).

"I learned about the microaggressions for the first time and it made me reflect on the presence of that in my life."

"I was wondering how I have benefited from privilege in ways that I was unaware previously."

"I took away that a lot of things are socially constructed so institutions play a role in leveling out the playing field. I found myself wondering how I can let other people be aware of these issues to make progress possible."
"I think I will be able to explain to lab members exactly how they make me feel as a marginalized member of the lab when they make certain comments. In particular, how that can affect our work as a group due to cognitive load."

The survey of coaches immediately following the in-person meeting revealed that they experienced personal growth from the culture- and diversity-related programming. When asked what they learned about others through the culture box activity, two of the coaches recalled:

"[The coaching group members] DO lead with nationality/ race in some instances, but people lead with different things. The key is to be aware, early on, what they lead with."

"I learned to see life through their eyes, which was very educational for me. The idea of discussing differences in a nonthreatening and supportive environment was excellent."

The coaches were also asked to share how they planned on applying what they have learned. Two stated:

"I will carefully look for and point out microaggressions with trainees. Much of the other component I already consider and employ in my mentoring."

"I really appreciated the quote in the online training about inclusiveness and having examples of success stories/role models for underrepresented groups. I'm thinking more now about how to integrate that idea into our ideas and my lab."

Group Facilitation: Insights and Skills. In the second cohort, we began incorporating an activity around group facilitation strategies as well as constructive and destructive group behaviors. During the first cohort, this discussion was initially reserved for only the coaches. However, the coaches remarked that this information would also be beneficial for students as a form of leadership development and to encourage them to be mindful of their behaviors within their newly formed groups. A group behaviors handout, modified from Brunt (1993), served as the basis for a small-group activity in which group members shared the constructive and destructive behaviors they lean toward when working in groups, as well as the behaviors that they would like to improve upon. In the second cohort's evaluation, a few mentees noted their appreciation for this exercise. Therefore, in the third cohort, we explicitly asked how they would use what they learned from this discussion in the future. One mentee noted that he/she would be more aware of the various roles people can play in a group and consider modifying his/her own behavior. Other comments included:

"I will be more aware of the different 'roles' that a person can have in a team. And definitely will try to understand and work with those different types of personalities."

"I think that I will be more cognizant of my strengths and weaknesses in a group setting and take a step back and do some introspection when I am thinking that the group is not productive." 
"I will be more aware of the role I am taking and maybe be able to change that role during discussions."

Immediately following the in-person meeting, the coaches were asked if they felt like their group implemented the facilitation skills. Two of the coaches stated:

"I feel that all were cognizant of their weaknesses and made sure that they gave other participants the opportunity to share."

"[The discussion did an] excellent job of encouraging others to talk about themselves and asking follow-up questions while people presented their culture box."

When asked the value of the day's activities, some of the mentees explained that the activities strengthened their connection to ASPET.

\footnotetext{
"[It was a] great way to identify others in ASPET. This is my first time attending the meeting, although I've been an ASPET member for years. It's great to instantly have some individuals at the meeting to network with."

"I thought it was helpful, it has also been nice to walk around and see some faces you know. Especially at such a big conference."
}

\section{What Took Place during the ASPET Annual Meeting, and How Do Network Members Interact with One Another?}

The second survey was distributed at the close of the ASPET annual meeting. It asked questions that probed specific activities during the meeting, as well as the combined experiences during the Network kickoff and the annual meeting.

Frequent Contact with Peers and Other Coaches. To help Network members "find" one another in among the many meeting participants, a simple badge ribbon with the Network name and a unique color was provided beginning with cohort 1 . Although the ribbon was a simple symbol of Network membership, it was obvious, and many commented on how it really facilitated connecting with current and past Network members. Overall, the great majority of mentees indicated that interacting with other Network peers from a half-dozen times during the meeting to "more than I can count" and "I really got to know a lot of my peers. I also got to know a few pretty well even though some were outside my coaching group." In later cohorts, many indicated they talked with Network members in previous cohorts who also had the badge ribbons, albeit less frequently than with their own cohorts. A high fraction also reported talking to one or more other coaches beyond their own group coaches.

Thus, the Network design and activities achieved the purpose of enabling frequent and valued connections among members beyond just those of the immediate coaching group.

Comfort with Raising Questions to Coaches and Coaching Group Members. As one indicator of the degree of trust and rapport developed among Network members, mentees were asked to rate their comfort raising personal and professional questions with their coach and group members. Data in Table 2 show a high level of comfort with both types of questions with both coaches and group members, a higher level of comfort with professional than personal questions, and very few instances of individuals being uncomfortable. Thus, the combination of the kickoff and continued associations during the ASPET annual meeting achieved the goal of setting the stage for engaged conversations during the yearlong virtual connections.

Perceived Usefulness of Group Conversations. The coaching group members were asked, "In what ways were the conversations with your coaching group useful." Many comments were provided, usually several by each person, and consistent themes emerged across cohorts. Listed in approximate frequency order they were:

- Listening to others' experiences; sharing experiences

- Realizing they are not the only one experiencing hardships; similar needs and situations

- Different perspectives on problems; diversity in thoughts

- Group bonding/camaraderie

- Concrete advice

- Conversations were free flowing/fluid/uninhibited

- Planning and setting expectations for the upcoming year

- Support/support group

\begin{abstract}
"One particularly useful aspect was listening to members more senior to me describe career decisions currently ongoing. It is difficult to speculate on these things, but hearing the details of someone else's experience helps give an idea of what things to try and be mindful of looking forward."
\end{abstract}

The list of useful elements of the Network conversations up through the meeting reflect very similar benefits to those previously observed in the more elaborate and extensive Academy group intervention, reflecting vicarious learning, social support, a "safe space," and concrete advice from unbiased peers and coaches.

TABLE 2. Comfort with raising personal and professional questions ( $n=49$ of 69 participants)

\begin{tabular}{lcccc}
\hline $\begin{array}{l}\text { How comfortable would you be } \\
\text { raising a... }\end{array}$ & $\begin{array}{c}\text { Very } \\
\text { comfortable (\%) }\end{array}$ & $\begin{array}{c}\text { Somewhat } \\
\text { comfortable (\%) }\end{array}$ & $\begin{array}{c}\text { Somewhat } \\
\text { uncomfortable (\%) }\end{array}$ & $\begin{array}{c}\text { Very } \\
\text { uncomfortable (\%) }\end{array}$ \\
\hline personal question to your coach? & 61 & 35 & 4 & 0 \\
professional question to your coach? & 86 & 12 & 2 & 0 \\
personal question to your group? & 47 & 35 & 4 & 6 \\
professional question to your group? & 86 & 14 & 0 & 0 \\
\hline
\end{tabular}


Perceived Usefulness of One-on-One Conversations with Coach. Across all three cohorts, mentees indicated that they had productive individual conversations with their group coaches; although this was suggested as a onetime 30-minute conversation, many reported multiple and/or much longer conversations. For the 2018 cohort, as an example, the range was only briefly (15 minutes) to $2 \mathrm{~h}$, with one mentee indicating 8 hours. Coaches never reported the individual time spent with mentees as a burden, usually appreciating getting to know each mentee, although some indicated it was a challenge given many commitments during the annual meeting.

In response to the question, "In what ways were the one-onone conversations with your coach useful?," the great majority of the mentees reported very positive responses that broke down into five primary themes.

- Deeper discussions of individual needs and career plans

- Formed closer relationship with coach

- Discussed career strategies and ways coaches could help

- Established expectations

- Talked about topics not easy to discuss in a group

"We were able to discuss my career goals and also gain insight on more about our identities and what we thought would be the best way to get me where I wanted to be next."

"It was a good time to talk specifics. In a group setting I don't like to bring things up that aren't at least somewhat applicable to everyone."

These useful aspects of the in-person, coach-mentee conversations during the annual meeting highlight the known benefits of personalized discussions with experienced, supportive coaches.

\section{What Was Achieved as a Result of the Virtual Meetings over 10-12 Months?} Coaches' Perspectives: Creating Spaces for Practical Mentoring and Difficult Topics. The coaches were interviewed 10 months after the in-person meeting, and all of them discussed forms of practical mentoring that occurred in their coaching group conversations. The topics were dependent on the career stages and needs/requests of the coaching group members, but often related directly to the job market and professional success. Over the course of the first three cohorts, a compilation of topics covered and resources used was created to serve as suggestions for each subsequent cohort. That list is provided in the Supplemental Material. In many instances, coaches connected group members to their own professional colleagues, who, for example, had recently negotiated a position or who had jobs in particular positions. On the surface, coaching group members benefited from the connections with their coaches by facilitating these network contacts. Coaches also discussed the strategies behind choosing particular people to bring in to speak. As one coach noted,

"I sort of heard [from the group], we actually want to talk to people who have jobs in the nonacademic world, but despite that feedback I still pulled in some academic people [laughs] ... I particularly pulled in academic people that were closer to their age, and had recently made the transition from postdoc to faculty because I just think in general, no matter the field, the further you get away from their age, the more you forget about what the obstacles, stresses and challenges are ... For the most part it was people coming on and actually talking about their experiences."

In this instance, the coach responded to the group's desire to hear from and talk to individuals working outside of academia. However, the coach also knew that their perceptions of academic careers might not be informed by those who had recently achieved them. Likewise, the coach knew there could be potential limitations of the relationships between mentees and their research mentors, especially with respect to career choices, but also as a result of mentoring style and/or familiarity with the mentee's issue at hand (e.g., Johnson, 2002; Handelsman et al., 2005; Abedin et al., 2012; Pfund et al., 2013, 2014; Meeuwissen et al., 2019).

One topic of conversation that came up frequently revolved around the issue of work-life balance. This came up in both a general way (e.g., how to navigate a job search with a spouse or partner), and in more specific ways (e.g., in their own unique circumstances). As one coach reported, during a group call with a guest speaker,

\begin{abstract}
"There were some questions about how she managed family life and having a kid with a really demanding job, and how to compartmentalize work and home life and things like that [...] the person who was asking these questions, we in the group know she's a new mother, but she was sort of apologetic about asking these questions, and so I made it clear that this is not only a really important sort of thing that we all deal with, even if we don't really talk about it so much, but that absolutely no apology was necessary. That in fact we should probably talk about things like this more often."
\end{abstract}

By validating the legitimacy of the questions and topic, both the person asking the questions and those listening will benefit from a release of pressure and open discussion of potential solutions and approaches. Skillful and effective research mentors can play this role, but too often trainees are afraid to bring it up. Also, doing so within a peer group is more beneficial, as solutions are more aligned with the age and career stage of those with the concerns.

The resonance of this topic among these early-career professionals also came up organically in other coaching groups. As one coach relayed,

\footnotetext{
"Yesterday we had a session on work-life balance that I thought was particularly interesting, because it was the first time the group kind of opened up about the struggles that they deal with, with partners and thinking about jobs. So, it became almost a little bit personal, which to me meant that the group had risen to a different level. We weren't just talking about issues. We were now talking about each other, and how we deal with problems and problems that they're thinking about dealing with, and they actually asked questions that were personal about how I dealt with things and so it was a different conversation whereas the others were more formal and about specific topics ... It became a little different discussion, which was nice because it meant that we kind of gelled as a group."
} 
Taking a risk to open a difficult topic and getting supportive responses from peers and the coach are critical interactions that foster trust in the group. While issues of work-life balance plague all professionals, they can be particularly salient for women in science, technology, engineering, and mathematics (STEM), who struggle with balancing work and family obligations (e.g., Cech and Blair-Loy, 2019). In the above example, the issue came up organically to a guest speaker who was a new parent. This provided the opportunity for a coaching group member, another new parent, to gain specific feedback. While these issues are important, there are often limitations for these kinds of conversations to occur in the laboratory or other professional settings. Coaching groups can provide that space.

\section{Impact of the Network 1 Year after In-Person Meetings}

The frequency and timing of virtual meetings, and especially the focus of each meeting, varied considerably among the 12 groups over three cohorts. Over the course of the three cohorts, a shift was made to encourage groups to identify topics for their virtual meetings and generate a schedule while at the meeting. Monthly meetings were more strongly encouraged, with a first meeting within a month of the ASPET meeting. Without this, some groups languished a bit, although most became more engaged and active during the year. About 10 months after the in-person meeting, a survey and individual phone interviews were used to assess the experiences of mentees, as well as the perceived value and impact. Given the small number of coaches, only interviews were conducted.

Overall, mentees were very satisfied with their experiences. Half of the mentees reached out to at least one other coach, indicating the goal of creating a broader Network beyond each small group had been achieved. The time committed to Network activities, as well as access to coaches, was seen as "about right". Most felt the virtual meetings covered all or most of everything they wanted, although some felt not all topics were germane to them. Finally, Table 3 shows the scaled responses to a number of statements related to potential objectives of the Network. Again, the data indicate positive impacts for all of the objectives, with some variation in strength, especially related to awareness of the challenge of those from UR groups.

Participants responded strongly that, as a result of the Network, they would be more likely to continue engaging with ASPET. Direct evidence for this intention was found from the observation that Network members were twice as likely to renew their ASPET membership in the following year compared with those in the same membership category who were not part of the Network. Across the cohorts, much insight into the perceived benefits of the Network were revealed by the survey question: "In what ways was the ASPET Mentoring Network most valuable or impactful for you?" Table 4 highlights the most frequent themes, along with an example of a quote aligned with each. Many of the comments and themes were very "practical" in nature and demonstrated the value to those with less access to robust mentoring or career development resources at their home institutions. A number of the themes from the survey are highlighted in Table 4 and include: learned about the experiences of individuals outside their programs, received help during job search, and formed a network outside their programs.

Although much fewer in number, responses to the question "In what ways did the ASPET Mentoring Network fail to provide what you hoped it would provide and/or fell short in the past year?" each year revealed areas for improvement. Most commonly, participants described their desires for more frequent meetings for the less active groups, notes on topics of interest to particular individuals that were not covered, and technology challenges that were frustrating. Some also commented that the virtual meetings did not allow them to bond as a group as much as they desired, but other groups were able to achieve this very well. The strength of the group bond appeared to be determined by the style of the coach, but also sometimes just the unpredictable "mix" of personalities and commonalities of six individuals being brought together for the first time.

TABLE 3. Mentee assessments of impacts of the Network

\begin{tabular}{|c|c|c|c|}
\hline As a result of participation in the ASPET Mentoring Network, I... & Cohort 1 & Cohort 2 & Cohort 3 \\
\hline am more aware of career options open to me. & 4.13 & 3.86 & 3.67 \\
\hline have a better idea of how to achieve my preferred career choice(s). & 4.13 & 4.05 & 3.67 \\
\hline feel my preferred career choice(s) are more achievable. & 4.20 & 4.00 & 3.80 \\
\hline see my peers in my coaching group as future colleagues and/or resources. & 4.67 & 4.10 & 4.60 \\
\hline see my coach as a future colleague and/or resource. & 4.73 & 4.38 & 3.87 \\
\hline $\begin{array}{l}\text { am more aware of the structural barriers that influence the experiences of individuals from } \\
\text { underrepresented groups. }\end{array}$ & $-^{\mathrm{b}}$ & 3.62 & 3.87 \\
\hline $\begin{array}{l}\text { am more equipped to address myself or assist others in responding to the challenges of being from } \\
\text { an underrepresented group. }\end{array}$ & 4.00 & 3.62 & $-^{\mathrm{b}}$ \\
\hline $\begin{array}{l}\text { appreciate more how each person brings their cultural as well as their scientific self to a research } \\
\text { group or larger scientific community. }\end{array}$ & 4.40 & 4.14 & 4.20 \\
\hline am more effective at facilitating small-group discussions. & $-^{\mathrm{b}}$ & 4.00 & 4.00 \\
\hline am more likely to continue engagement with ASPET for my professional community. & 4.73 & 4.24 & 3.93 \\
\hline am more likely to recommend ASPET as a professional society to my colleagues. & 4.53 & 4.29 & 4.33 \\
\hline \multirow[t]{2}{*}{ am more likely to recommend the ASPET Mentoring Network to my colleagues. } & 4.60 & 4.43 & 4.27 \\
\hline & $n=11$ & $n=21$ & $n=15$ \\
\hline
\end{tabular}

aChoice options were: 1 = strongly disagree, 2 = disagree, $3=$ no change, 4 = agree, $5=$ strongly agree.

${ }^{\mathrm{b}}$ This question was not asked to participants in this cohort. 
TABLE 4. In what ways was the ASPET Mentoring Network most valuable or impactful for you?

\begin{tabular}{|c|c|}
\hline Theme & Example \\
\hline $\begin{array}{l}\text { Learned about the experiences of } \\
\text { individuals outside of their programs }\end{array}$ & $\begin{array}{l}\text { "Just interacting with people in different programs with different experiences was invaluable. I felt } \\
\text { able to contextualize my experience within the greater scientific community." }\end{array}$ \\
\hline Received help during job search & $\begin{array}{l}\text { "[Coach name] was an excellent mentor. My main aim was to improve my chances of getting a } \\
\text { job, and [coach name] and the group helped me to achieve this goal. From editing my } \\
\text { interview presentation, to discussing offer negotiations. I cannot say enough good things about } \\
\text { how helpful this has been for me." } \\
\text { "The most valuable aspect of the mentoring network was having mentors available to give advice } \\
\text { whenever problems arose. Searching for a job is a very difficult task and having professionals } \\
\text { on hand to provide guidance made the process a little less nerve wracking." }\end{array}$ \\
\hline $\begin{array}{l}\text { Received help in preparing materials } \\
\quad \text { (e.g., CV) }\end{array}$ & $\begin{array}{l}\text { "The mindset you develop from joining a mentoring network is incredible-you gain confidence } \\
\text { and courage to start networking. The gist is, ASPET Mentoring Network grooms you to do well } \\
\text { in everything from résumés to informational interviews together with the power of networking } \\
\text { with someone outside of your field of work." }\end{array}$ \\
\hline $\begin{array}{l}\text { Formed a network outside of their } \\
\text { programs or mentors' networks }\end{array}$ & $\begin{array}{l}\text { "I gained a valuable mentor who has a wealth of career knowledge and experience. [Coach name] } \\
\text { was even able to help me identify and secure a speaker for a symposium I am chairing-direct } \\
\text { evidence that this is a solid networking opportunity." } \\
\text { "Through my coach I was able to network with scientists abroad and learn about alternative career } \\
\text { options." }\end{array}$ \\
\hline Promoted cultural awareness & $\begin{array}{l}\text { "I felt the diversity awareness discussion at the ASPET meeting was incredibly eye-opening and } \\
\text { not a topic I would have engaged with if not for the mentoring program." } \\
\text { "Helped broaden my network and experience with people from diverse culture backgrounds. } \\
\text { Allowed me to understand the influence of culture and self in career development and choice." }\end{array}$ \\
\hline
\end{tabular}

In addition to the survey data, all mentees were invited to participate in semistructured phone interviews with one of the SCRDG team members. Although labor-intensive, these interviews revealed much deeper and more complete information on impacts and value of the Network than surveys could ever hope to achieve.

Some of the groups built on tools and concepts introduced during the in-person meeting. For example, the IDP was new to many if not most of the mentees. As one mentee noted:

"I had never heard of an IDP before. And [coach name] definitely did encourage us to do it, so I finally did it, and I really wasn't sure what I wanted to do when I graduated. Where was my mind really trying to take me? And it really helped, and I've been talking to members of my faculty because they know people in other areas as well, to try to set up meetings so I can kind of get a gauge of what it is these people do on a daily basis. Is this an area that, really, I can see myself [in] for the next $5,10,15,20$ years?"

The introduction and support to complete the IDP proved very beneficial to this mentee, who was then able to use it to guide discussions with mentors at his/her home institution to gain insight and exposure to various careers.

The content of virtual meetings was left to the discretion of the coach and coaching groups. Many mentees discussed perceived benefits of their various activities in the coaching group interactions throughout the year. For example,

"Even if [coach name] doesn't have all the answers, she knows people who know people, and so she introduced us to a few other people... so I met with [my coach name] one-on-one and then she introduced me to another [coach name] who spent a few minutes talking to me about other career options ... so aside from the culture box and aside from her speaking to us about her experiences and then telling us you know we get to design the next year for our group the way we want it to be. It was an amazing service [...] I would say talking to people outside of academia, the other mentors she brought was [sic] very impactful, and it just helps me to see there are better options. It doesn't have to be one way."

This mentee, like many others, discussed the value of having a coaching group model that adjusted to the needs of the group members.

Mentees discussed key instances when the coach and coaching group connections proved useful, such as providing practical advice on things like curricula vitae (CVs), résumés, and presentations; providing insights and advice on job market processes; and providing general support, including personal perspectives on the nature of various career paths. For example, many mentees discussed coach-facilitated group meetings in which coaching group members discussed and shared CVs and cover letters.

"One session that was especially useful was the CV session. We basically just went through our CVs and highlighted things that were unclear, formatting issues, all that kind of stuff and just improved upon it, and now I believe that my CV reads much better, it has a much more professional appearance, so that was definitely helpful."

This tangible knowledge that can come out of group mentoring contexts is amplified by providing feedback to others and hearing feedback provided to others.

Some mentees described situations in which the coaching group connections were invaluable for the job search process. After receiving an invitation for a job interview, one mentee reached out to the coaching group for feedback. As this mentee said, 
"[The coaching group's] help was really instrumental in my interviewing process. So, after I landed the interview, [coach name] suggested I send the group my presentation and I got feedback from a number of people that really helped, so it was nice. I really appreciated that and then even afterwards after I was offered the job."

The mentee then continued the conversation with the coach:

"We had some good discussions about negotiations, and I was at a complete loss because this is my first academic job and I just didn't really know the field and luckily [coach name] was in the pharmaceutical industry [in the city] where I was going, and so [the coach] had a lot of knowledge specifically that was helpful and for me, figuring out what the offer was really about [laughs]."

At minimum, the coaching model provides a perspective to supplement those from their home institution (e.g., Thakore et al., 2014). Conveniently, the connection available to this mentee were specific both to this career and the region in which the position was located.

Relatedly, many other mentees discussed the value of the connections with their coach and coaching group, who provided insights into a variety of career perspectives and experiences. A mentee discussed the benefits of the career experiences of others in the coaching group:

"I get to see how much postdocs are doing if I wanted to go in that direction towards academia. I didn't actually know how much time they spend doing grants and writing their own grants and trying to get their own stuff started as opposed to just doing their own lab work. I had no idea until I talked to the other postdocs in the mentoring network. It'll just help me weigh what I want to do with my work life balance and everything like that, and it'll help me make a better-informed decision on what's good to do for me and family in the future so I think, definitely I've learned a lot from that audience."

These kinds of career insights can be missing from a traditional $\mathrm{PhD}$ program, where students are constrained within their cohorts and there are fewer opportunities to discuss both the positive and negative components of an academic careerparticularly the dynamics of work-life balance that a future professional must weigh.

One mentee, whose coach had career experiences in both academia and industry, valued the perspectives of both sides:

\footnotetext{
"I think with the help of [coach name] and the invited guests, I saw the advantages and disadvantages of working in and out of academia. It definitely gives you more money not staying in academia. I am not sure about the flexibility, especially one day to the other. But I think that the type of work that you would have to do out of academia is totally different than academia, and I think maybe in academia, you really have to know the right people in order to progress or advancing [sic] your career. I actually got to know people [who] stay in academia, when it comes to grant review and writing papers. I think I wish I would [have known] this and I would have [come] here before defending my $\mathrm{PhD}$, I think that would be different."
}

Similarly to perceptions of students in the Academy groups, many ASPET mentees displayed learning vicariously from their coaches about the components of various careers (Williams et al., 2016a). The degree of exposure varied by coaching group, depending on the career path of the coach. Many ASPET coaches have varying career experiences, including in a variety of nonacademic careers, and some in both academic and nonacademic careers. This exposure can provide supplemental insights not available to mentees at their home institutions. Also, given the informal and personal nature of the coaching group dynamic, the pros and cons of various careers can be discussed in this safe space. Finally, providing insights to the group amplifies the "reach" of a mentor for the same amount of investment of time and effort.

Overall, most of the ASPET mentees perceived some value from the coaching group connections. In general, this was rooted in the perception of benefits from a group of peers outside of one's home institution. This is similar to the feedback about the Academy coaching groups (e.g., Williams et al., 2016a,b; 2017). As one mentee reflected, one benefit of the coaching groups is "having someone outside your lab other than your PI to talk to about some things which are going on in your lab, which you cannot always talk in the lab about."

Some of the mentees discussed feeling isolated in their own programs, such as being in a small graduate program, or missing the interpersonal connections during the day-to-day science benchwork.

\begin{abstract}
"To be honest with you, for me being a grad student [at my institution] it's so finite here. I don't see a lot of grad students get together and discuss what they're doing and what's a problem and how the senior-most people guide them or mentor them. So, all [that] information was readily available to me [at the ASPET Mentoring Network], so those two days were really fun days."
\end{abstract}

This experience is similar to the emotional support that this level of connection with people outside your home institution can provide (Williams et al., 2017). What was especially unique about the ASPET groups is that they were all rooted in pharmacology. In fact, this was particularly helpful for one mentee:

\footnotetext{
"I'm in kind of a small program, so it's nice to be able to build a network outside of my university of other pharmacologists around the country and try to see what other people are up to and they're doing."
}

While the usefulness of the mentor-mentee relationship can be assumed, the peer-to-peer connections within the coaching groups provided mentees networking opportunities that have the potential to turn into useful relationships in the future.

The traditional coach-mentee relationship is observed through the mentees' experiences with their coaches in terms of expert experience and insights. On the other hand, the uniqueness of the coaching group model is that the peer-peer connections provided opportunities for advice and perspectives into immediate experiences (e.g., job success or grant application success). As one mentee discussed, 
"One of the group members, she tried to start her own labshe wants her own lab, she doesn't necessarily want to be associated with an academic institution-and the steps that she's taking towards getting to where she wants to be [...] she's sort of like a mentor. She's like somebody you want to emulate just because of her drive and her methodology, and how she thinks about things is very logical and critical. Everybody else [in my coaching group] is, too [...] they all have their own areas that they specialize in and they're very knowledgeable about their science and they are always thinking about different ways to do things that can help your process."

Again, these opportunities provide insights traditionally not available in the confines of a traditional graduate program and increase the "reach" of peer mentoring and networking (e.g., Pawley et al., 2014; Anderson et al., 2019).

One major benefit of the ASPET mentoring network came from mentees' increased knowledge and awareness of ASPET as a professional society. Many students discussed the usefulness of the mentoring network for their own future experiences at ASPET and the annual meeting:

"I did remember those days in the early years of my grad career $[\ldots]$ at that time I didn't have the mentoring network, so I was just roaming for the selected times and selected posters which I just browsed through the [conference] handout, but now when I have a mentoring network, I have a whole broad spectrum of people [who] I know that I [invite] to those kinds of events that I'm presenting."

"I joined ASPET specifically for the mentoring group, so it had a tremendous impact on getting me involved with ASPET. I definitely would like to attend future meetings. My focus, my lab generally prefers to go to [another conference], so we usually direct our resources there, but in my professional future I definitely hope to attend more meetings."

Finally, even coaches recalled in their interviews personal improvements since starting the group. Coaches reflected on their approaches to working with their coaching groups. Overall, coaches solicited ideas from group members on topics to cover in their virtual meetings. This proved to be the most effective method for planning the virtual group meetings, when discussions could be more organic than formal. Coaches were aware of the benefits of the ASPET program's coaching group model. As one coach reflected,

"A lot of it is having them mentor each other, right? Because you have a group and learning a little bit about each of them, which initially I did just by asking questions about their strengths and weaknesses, that I would just pose the question like hey, can you comment on such and such because so and so has this question, right? It's almost like having them learn to mentor each other. That's different than one-on-one mentoring where you're just saying things. It's like, that's my viewpoint here, [and] everybody has a viewpoint."

As established from the original Academy design (Thakore et al., 2014), a group can also serve the benefit of peer-to-peer/ near-peer mentoring. This can be especially useful for group members who range in their professional status (e.g., advanced graduate student, postdoctoral scholar, and early-career professional). In this last reflection, it is also apparent that this opportunity can provide the training and preparation needed for effective peer mentoring.

Many coaches also committed to both meeting with coaching groups, and meeting one-on-one with individual group members. This form of individual mentoring served as a useful supplement to the coaching group model. As one coach noted, the one-on-one conversations provided opportunities to discuss issues related to racial and gender inequality:

"I don't know if people were embarrassed to bring those topics up or just thought that maybe the rest of the group wasn't interested ... In addition to the group meetings, I tried to talk to each person at least once on the phone, and [issues of diversity] came up there, especially from the females, [on issues such as,] I don't know how to be assertive, and coming off a certain way."

\section{DISCUSSION}

Overall, based on feedback data, informal verbal comments, and observations, the ASPET Mentoring Network "worked; it is now seen as an important activity and member benefit to be sustained by the ASPET leadership. Applications to the program have been robust since its inception and now number two to three times the number who can be accommodated. With a few exceptions, PhD students and postdocs related that the Network met or exceeded their expectations, and that they valued what they got from it. In some ways, the group mentoring design created similar environments and interactions as the initial Academy experiment, but in some ways it turned out quite differently. Similarities included: 1) a very rapid engagement among mentees with one another during the initial meeting (although the methods used to achieve this were very different); 2) a strong sense of comfort and trust among most mentees and coaches; 3) value/impacts coming from peers, near peers, and coaches; and 4) vicarious learning and social supports being very evident within the coaching groups.

But the Network turned out to provide some very different elements than those seen in the Academy. Probably the most striking was the frequency with which direct connections to networks of coaches and others led to actual job opportunities. This likely resulted from a number of factors. First, postdocs are included in the program, and were not in the Academy, which made job hunting a primary focus. Second, with everyone being in a similar or related field, the chances that networks would overlap in expertise and career objectives was much higher. Third, at least half of the coaches in each cohort are currently in or have been in nonacademic positions, so they could provide a wealth of knowledge and expertise not readily available to many of the mentees. Fourth, by framing the in-person meeting as starting from each group focusing on "What would you like to get from our year together?," a very different context was established compared with the Academy with its focus on progressing through the $\mathrm{PhD}$ and the next steps after the $\mathrm{PhD}$.

A major difference between the Academy and the Network comes from the Network being situated within the context of a society built around common scientific interests and the immediate progression into the annual meeting. This model allowed 
for direct and timely new professional network members to be established. Although this did not come up in evaluations (nor was it asked directly), this closer tie to common interests and identity did come up in mentee-mentee and mentee-coach conversations; the interest and identity alignment was closer in the Network than in the Academy, which included all of the biomedical sciences. The value of this was shown with a high fraction seeing peers and coaches as future colleagues. It also was played out and solidified through mentees and coaches continuing to meet and converse during the ASPET annual meeting. The surveys also provided evidence of the intention to stay connected to ASPET. ASPET membership renewal rates for alumni of the Network confirmed this concrete impact.

Another difference with the Network is the somewhat lesser focus on racial and ethnic diversity and a broader focus to include international diversity by including international graduate students and trainees. This was not possible in the Academy, as it was funded by NIH, which stipulated only U.S. citizens and permanent residents were eligible. Because the Academy included longer periods of time during in-person meetings and multiple meetings over $2-3$ years, it was possible to introduce activities and dialogue that went much deeper into sensitive topics around race, racism, privilege, and bias. Relationships developed were generally deeper than what was possible in the Network. However, by using tools like the online module and culture box, neither of which were available at the time of the Academy, the goal of heightening awareness of working together across social and identity differences was at least initiated. As noted earlier, the conversations initiated as a result of the culture box were unique and beyond what would likely happen so quickly in the context of people meeting for the first time at a scientific conference. Mentees and coaches commented on this unique exercise, and the depth of insights they made about one another was striking. Very rapidly, people saw one another as scientists and people and appeared comfortable seeing how the two can intersect. Likewise, discussions around the online module brought out many important reflections and sharing of experiences, but these were not captured directly and did not appear prominently in the interview protocols.

The coaches who participated were already representative of highly experienced professionals and people who have informally or formally "mentored" throughout their years and are aware of racial and gender underrepresentation in their fields. All of the coaches acknowledge the usefulness of the culture box activity, which was also discussed in the coach trainings. As established by Byars-Winston et al. (2018), these kinds of activities around cultural awareness are effective for breaking down assumptions and stereotypes about UR groups. It is important to note that the variance in mentee engagement with the Mentoring Network will determine the amount of support received from it. However, our research findings suggest that it is important to set expectations for the coaches to be proactive and engage regularly with their groups.

There were many goals in creating the Network, both practical and theoretical. With respect to increasing knowledge of and access to careers beyond academia, the Network was very successful due to the broad career base of the coaches and access to the knowledge of peers and near peers. The Network's impacts on diversity of the scientific workforce were harder to measure, but the level of comfort and engagement among the highly diverse trainees was palpable. Several UR trainees expressed appreciation that their ongoing experiences were named and validated, as with the use of the concept of microaggressions. Many non-UR individuals learned about or had first conversations about inequalities in science, which, as some noted in interviews, impacted their perspectives on their training and career environments. Expansion to include mentees from other countries also broadened dialogue, which is likely to improve cross-cultural communication in the future.

From a theoretical perspective, it was clear in our observations of the groups that most participants were gaining access to the breadth of accumulated knowledge of their coaches and colleagues. Although this knowledge sharing was more "direct" than some constructs of cultural capital would suggest, it was a vivid manifestation of how access to professional knowledge is so uneven within research training. The acquired access and knowledge went beyond the initial in-person meetings and into the ability to gain more through virtual meetings. Finally, because the Network was locally situated within the ASPET community of practice, it would necessarily play a pivotal role in generating a sense of belonging for many participants. The Network itself is the guided entrée into the community. It is not hard to imagine that all of these practical and theoretical benefits would occur within other professional fields and settings.

\section{Limitations}

Although not a direct goal of creating the Network, an obvious question is whether the perceived and real benefits of the program can be generalized to other coaching or mentoring interventions. The evaluation data reveal the reactions to, feedback about, and benefits of the Network from the perspectives of mentees and coaches involved. Direct impacts over the course of the year in the Network, such as contacts leading to jobs, are reported by some. However, the Network was not designed as an experiment to compare it with any other professional development activity or any additional activity at all. Also, it was not designed to help participants achieve any particular outcome or track their scientific or career "outcomes" over time. Thus, it cannot be concluded that it "worked" for a particular outcome or that it is better than any other professional development activity for either perceived value or outcomes. It would be very interesting to follow participants over time to see whether perceived and real benefits grow, but this is beyond the scope of the resources currently available.

\section{CONCLUSION}

The opportunity to implement this kind of programming within a scientific society makes it easily translatable to any discipline. Many professional societies have resources allocated for activities like mentoring initiatives, and with student travel awards can make the coordination of the mentees cost-effective. Additionally, the physical space of a yearly research conference provides the infrastructure to meet as a group in person for 2 to 3 days. Advances in virtual group communication not only make it easier to stay in touch throughout the year, but also easier to invite guest speakers-as many of the coaches discussed doing.

While it is too early to estimate the long-term effectiveness on mentees, we can look at this combination of self-reported perceived benefit and intention to return and continue to follow mentees longitudinally with a survey to track meeting attendance 
and connection with others from the Network. For example, do mentees feel more engaged with the ASPET conference and community? What is the benefit of connection of people at this level in the same discipline? Do professional networks persist over time? Do the professional connections between mentees and those in their coaches' personal networks develop?

\section{ACKNOWLEDGMENTS}

This work was supported by grants from the NIH: R01 GM107701, R35 GM11814, and U54 GM119023. It was also supported by a Big Idea award from ASPET. We would also like to acknowledge the enthusiastic commitment of time and insights of all of the ASPET coaches during the years reported on here and continuing in the current and upcoming years.

\section{REFERENCES}

Abedin, Z., Biskup, E., Silet, K., Garbutt, J. M., Kroenke, K., Feldman, M. D., .. Pincus, H. A. (2012). Deriving competencies for mentors of clinical and translational scholars. Clinical and Translational Science, 5, 273-280.

Anderson, M. K., Anderson, R. J., Tenenbaum, L. S., Kuehn, E. D., Brown, H. K., Ramadorai, S. B., \& Yourick, D. L. (2019). The benefits of a near-peer mentoring experience on stem persistence in education and careers: A 2004-2015 study. Journal of STEM Outreach, 2(1). doi:10.15695/jstem/ v2i1.01

Bourdieu, P. (1985). The forms of capital. In Richardson, J. (Ed.), Handbook of theory of research for the sociology of education (pp. 241-258). Westport, CT: Greenwood.

Brunt, J. (1993). Facilitation skills for quality improvement. Quality enhancement strategies. Madison, WI. https://www.vetmed.wsu.edu/docs/ librariesprovider16/Docs-- -Teaching-Academy/day-2 - (jan-15) constructive_destructive_grp_behaviors.pdf?sfvrsn=3f7703b_0

Byars-Winston, A., Womack, V. Y., Butz, A. R., McGee, R., Quinn, S. C., Utzerath, E., ... \& Thomas, S. B. (2018). Pilot study of an intervention to increase cultural awareness in research mentoring: Implications for diversifying the scientific workforce. Clinical and Translational Science, 2(2), 86-94.

Cech, E. A., \& Blair-Loy, M. (2019). “The Changing career trajectories of new parents in STEM." Proceedings of the National Academy of Sciences USA, 116(10), 4182-4187. doi: 10.1073/pnas.1810862116

Diversity Programs Consortium. (n.d.). Home page. Retrieved September 5 , 2019 from www.diversityprogramconsortium.org

Gazley, J. L., Remich, R., Nafzigger-Hirsch, M. E., Keller, J., Campbel, P. B., \& McGee, R. (2014). Beyond preparation: Identity, cultural capital, and readiness for graduate school in the biomedical sciences. Journal of $R e-$ search in Science Teaching, 51(8), 1021-1048.

Handelsman, J., Pfund, C., Lauffner, S.M., \& Pribbenow, C.M. (Eds.). (2005). Entering mentoring: A seminar to train a new generation of scientists. Madison: University of Wisconsin Press.

Harrison, C., \& Tanner, K. D. (2018). Language matters: Considering microaggressions in science. CBE-Life Sciences Education, 17(1), fe4.

Johnson, W. B. (2002). The intentional mentor: Strategies and guidelines for the practice of mentoring. Professional Psychology: Research and practice, 33(1), 88

Jones, H. P., McGee, R., Weber-Main, A. M., Buchwald, D. S., Manson, S. M., Vishwanatha, J. K., \& Okuyemi, K. S. (2017). Enhancing research careers: An example of a US national diversity-focused, grantwriting training and coaching experiment. BMC Proceedings, 11(Suppl 12), 183-200.

Lave, J., \& Wenger, E. (1991). Situated learning: Legitimate peripheral participation. Cambridge, UK: Cambridge University Press.

Lenzi, R. N., Korn, S. J., Wallace, M., L Desmond, N. L., Labosky, P. A. (2020). The NIH "BEST" Programs: Institutional Programs, the Program Evaluation, and Early Data. FASEB Journal, 34(3), 3570-3582.
McGee, R., \& Keller, J. (2007). Identifying future scientists: Predicting persistence into research training. CBE-Life Sciences Education, 6(4), 316-331.

Meeuwissen, S. N. E., Stalmeijer, R. E., \& Govaerts, M. (2019). Multiple-role mentoring: Mentors' conceptualisations, enactments and role conflicts. Medical Education, 53(6), 605-615. doi: 10.1111/medu.13811

National Academies of Science, Engineering and Medicine (NASEM). (2011) Research training in the biomedical, behavioral, and clinical research sciences. Washington, DC: National Academies Press. Retrieved September 5, 2019, from: www.nap.edu/catalog/12983/researchtraining-in-the-biomedical-behavioral-and-clinical-research-sciences

NASEM. (2014). The postdoctoral experience revisited. Washington, DC: National Academies Press. Retrieved September 5, 2019, from www.nap edu/catalog/18982/the-postdoctoral-experience-revisited

NASEM. (2018). Graduate STEM education for the 21st century. Washington DC: National Academies Press. Retrieved September 5, 2019, from www.nap.edu/catalog/25038/graduate-stem-education-for-the -21st-century

National Institute of General Medical Sciences. (2017). National Institute of General Medical Sciences Ruth L. Kirschstein National Research Service Award (NRSA) Predoctoral Institutional Research Training Grant (T32). Retrieved September 5, 2019, from https://grants.nih.gov/grants/guide/ pa-files/par-17-341.html

National Science Foundation. (2009). Chapter II-Proposal preparation instructions. Retrieved September 5, 2019 from www.nsf.gov/pubs/ policydocs/pappguide/nsf09_29/gpg_2.jsp

Pawley, A. L., Carberry, A. R., Cardella, M. E., Carnasciali, M. I., Daly, S. R., Gorlewicz, J. L., ... \& Lande, M. (2014). The PEER Collaborative: Supporting engineering education research faculty with near-peer mentoring unconference workshops. ASEE Annual Conference and Exposition, Conference Proceedings held June 15-18, in Indianapolis, IN. https:// www.asee.org/public/conferences/32/papers/9048/view

Pfund, C., House, S. C., Asquith, P., Fleming, M. R., Buhr, K. A., Burnham, E. L., ... \& Sorkness, C. A. (2014). Training mentors of clinical and translational research scholars: A randomized controlled trial. Academic Medicine 89, 774-782.

Pfund, C., House, S., Spencer, K., Asquith, P., Carney, P., Masters, K. S., ... \& Fleming, R. (2013). A research mentor training curriculum for clinical and translational researchers. Clinical and Translational Science, 6, 26-33.

Remich, R., Jones, R., Wood, C. V., Campbell, P. B., \& McGee, R. (2016). How women in biomedical PhD programs manage gender consciousness as they persist toward academic research careers. Academic Medicine, 91(8), 1119-1127.

Remich, R., Navzigger-Hirsch, M. E., Gazley, J. L., \& McGee, R. (2017) Scientific growth and identity development during a postbaccalaureate program: Results from a multisite qualitative study. CBE-Life Sciences Education, 15(3), 1-12.

Sue, D. W. (2013). Race talk: The psychology of racial dialogues. American Psychologist, 68(8), 663

Thakore, B. K., Naffziger-Hirsch, M. E., Richardson, J. L., Williams, S. N., \& McGee, R. (2014). The Academy for Future Science Faculty: Randomized controlled trial of theory-driven coaching to shape development and diversity of early-career scientists. BMC Medical Education, 14(1), 160.

Wenger, E. (1998). Communities of practice: Learning, meaning, and identity. Cambridge, UK: Cambridge University Press.

Williams, S. N., Thakore, B. K., \& McGee, R. (2016a). Coaching to augment mentoring to achieve faculty diversity: A randomized controlled trial Academic Medicine, 91(8), 1128-1135.

Williams, S. N., Thakore, B.K., \& McGee, R. (2016b). Career coaches as a resource for racial and ethnic minority PhD students in the biomedical sciences: A qualitative study. PLOS ONE, 11(7), e0160038. doi: 10.1371/journal.pone.0160038

Williams, S. N., Thakore, B. K., \& McGee, R. (2017). Providing social support for underrepresented racial and ethnic minority $\mathrm{PhD}$ students in the biomedical sciences: A career coaching model. CBE-Life Sciences Education, 16(4), ar64. 